\title{
THE ACQUISITION OF CLICKS BY XHOSA-SPEAKING CHILDREN
}

Sandile Gxilishe

University of Cape Town

The article deals with the order of emergence of click consonants and the nature of click inventory. It reveals the course of development and differentiation of a phonological repertoire of a type different from those studied in depth to date.

The sample consists of 10 children, three males and seven females between 1:0 and 3 years old. The study shows ample evidence of the extensive use of question and prompting routines directed at these Xhosa-speaking children and explains why these children learn these clicks so early despite how marked they are.

Results describe the order of acquisition; the appearance of all basic clicks; the tempo between 1:7 and 2:0 years; the period of occurrence of a spurt; and the development of voiceless to voiced and nasalized clicks.

\section{INTRODUCTION}

One of the most fascinating things about the spoken word of the indigenous people of Africa South of the Sahara is that their languages have structures that are unique to the region. Prominent among these is the phenomenon involving click like sounds.

Click sounds are predominantly used by the San (Bushmen) and Khoekhoe (Hottentots). But these groups jointly known as Khoesan also share the click sound in varying degrees with other indigenous people speaking language such as Xhosa, Zulu and Southern Sotho. The Cape Khoekhoe have had a profound effect on the genetic features of many South Africans. The language has exerted an influence on the development of Afrikaans and has extensively restructured the phonological systems of Xhosa and Zulu, greatly enriching the lexicons of these two languages in the process (Mesthrie, 2002).

One of the distinct areas that can be identified in this process is in the east between the Kei and Keiskama rivers, where the Khoekhoe were 'incorporated by the expanding Xhosa chiefdoms during the early 1700s' (Harinck, 1972:158). Contact and interaction between Xhosa and Khoe was facilitated by the fissiparous tendency in the Xhosa social structure and by similarities in their respective social organisation' (Harinck, 1972:158). This resulted in assimilation of the Khoekhoe into Xhosa lineages and Xhosa into Khoe chiefdoms. The wellknown result of this intimate and long contact was the incorporation of a large vocabulary containing adapted click consonants, which affected the phonological system (Harinck, 1972: Herbert, 1990a, 1990b; Lanham, 1964; Louw, 1974, 1979). A similar process affected Zulu 
in the same way (Louw, 1979). It is frequently estimated that about 15 per cent of Xhosa and Zulu words have clicks.

The nature of the Xhosa vocabulary incorporated from Khoekhoe allows some inferences to be made about the social relationships between Khoe and Xhosa. Specialised cattle terminology, and religious concepts and words such as ikhoboka, 'bondsman' (khowob 'bondsman'). There are examples of hunting terminology as in nqakathela 'catch', nqamula 'catch' ncam 'quite', cattle terminology like iziqa 'sinew' xhela 'slaughter and wild life terminology, for example uxamu 'leguan', xinga 'jammed' and ngxama 'hurried'.

\section{Consonant inventory}

Clicks not only occur as interjections or in non-linguistic gestures in some languages, but they also occur in the consonant inventory of various languages in Southern and East Africa (Maddieson \& Ladefoged, 1993; Lewis \& Roux, 1996). In an article published in the New York Times, Wade (2003: 2) points out that a new genetic study underlines clicks their heritage from a particular group of languages spoken by an ancient population. Most of the surviving click speakers live in Southern Africa. Outside of Africa, the only language known to use clicks is Damin, an extinct aboriginal language in Australia that was taught only to men for initiation rites. There are other reasons to assume that the click languages may be very old. They seem to have been part of the first fully articulate human language that appeared among some group of early human language that appeared among some group of early humans 50,000 years ago. Current users of clicks, particularly a group of huntergatherers of the Kalahari, belong to an extremely ancient genetic lineage, according to DNA analysis (Wade, 2003: 2).

Xhosa is a Nguni language spoken in Southern Africa by approximately 8.2 million South Africans. It is predominantly spoken in the Eastern Cape by approximately $83 \%$ of the population and in the Western Cape by approximately $19 \%$.

\begin{tabular}{|l|l|c|c|c|}
\hline \multicolumn{2}{|c|}{} & Dental & Lateral & Alveo-palatal \\
\hline \multirow{4}{*}{ Oral } & Voiceless & $\mathrm{c}$ & $\mathrm{x}$ & $\mathrm{q}$ \\
\cline { 2 - 5 } & Aspirated & $\mathrm{ch}$ & $\mathrm{xh}$ & $\mathrm{qh}$ \\
\cline { 2 - 5 } & Voiced & $\mathrm{gc}$ & $\mathrm{gx}$ & $\mathrm{gq}$ \\
\hline Pre-nasalized & Voiceless & $\mathrm{nc} / \mathrm{nkc}$ & $\mathrm{nx} / \mathrm{nkx}$ & $\mathrm{nq} / \mathrm{nkq}$ \\
\cline { 2 - 6 } & Voiced & $\mathrm{ngc}$ & $\mathrm{ngx}$ & $\mathrm{ngq}$ \\
\hline
\end{tabular}

Table 1: Xhosa clicks (Downing 2001) 


\begin{tabular}{|c|c|c|}
\hline Orthographic & Phonetics & Word \\
\hline representation & representation & \\
\hline \multicolumn{3}{|l|}{ Dental clicks } \\
\hline c Dental Click & {$[-]$} & caca (be clear) \\
\hline nc Nasalized Dental Click & {$[-\&]$} & inconco (liquid for babies) \\
\hline ch Aspirated Dental Click & {$[-\hat{1}]$} & chacha (recuperate) \\
\hline gc Voiced Dental Click & {$[-3]$} & gcagca (elope) \\
\hline ngc Nasalized Voiced Dental & {$[-\& 3]$} & ingcongconi (a mosquito) \\
\hline nkc Nasal+Dental Click & {$[\mathrm{N}-]$} & nkcenkceshela (irrigate) \\
\hline \multicolumn{3}{|l|}{ ALVEO PALATAL CLICKS } \\
\hline q Palatal Click & {$[<]$} & qaqamba (shine/throb) \\
\hline nq Nasalized Palatal click & {$[<\&]$} & umnqonqo (spinal cord) \\
\hline qh Aspirated Palatal click & {$[<\hat{1}]$} & uqhoqhoqho (windpipe) \\
\hline gq Voiced Palatal click & {$[<3] 3$} & gqogqa (search) \\
\hline ngq Nasalised Voiced Palatal click & {$[<\& 3]$} & isingqengqelo (a couch) \\
\hline nkq Nasal \& Palatal click combination & {$[\mathrm{N}<]$} & nkqonkqoza (knock) \\
\hline \multicolumn{3}{|l|}{ ALVEOLAR LATERAL CLICKS } \\
\hline x Lateral click & {$[,]$,} & ixakuxaku (untidy person) \\
\hline nx Nasalised Lateral click & $[,)]$, & inxanxadi (butcher-bird) \\
\hline xh Aspirated Lateral click & {$[, \hat{1}]$} & xhaxha (chop meat) \\
\hline gx Voiced Lateral click & {$[,, 3]$} & gxagxamisa (hasten) \\
\hline ngx Nasalised Voiced click & $[,, 3)]$ & ngxongxa (lie on the back) \\
\hline nkx Nasal \& Lateral click combination & {$[\mathrm{N},]$,} & inkxaso (support) \\
\hline
\end{tabular}

\section{Table 2: Click phonemes occurring in Xhosa}

A pronunciation of the above clicks shows that clicks always stand out from the sounds around them. This is because many clicks contain a great deal of acoustic energy. Coarticulation with the following vowel is difficult to achieve (Ladeforged \& Traill, 1994). As a class, clicks are probably the most salient consonants found in a human language. They are virtually never confused with non-click consonants.

The early acquisition of click consonants is of special interest to South African SpeechLanguage Pathologists, linguists and educators is the early acquisition of click consonants. This is because as most deviations in normal phoneme acquisition involve consonants. Apart from the research done on the acquisition of clicks and related issues by Doke (1926), Lanham (1969), Magi (1990), Connelly (1984), Herbert (1990), Mowrer and Burger (1991), Lewis (1994a; 1994b) and by Lewis and Roux (1996), not much research has been done on the acquisition of these sounds since Xhosa was first written in 1823. With the exception of some few studies (see Suzman, 1982; Connelly, 1984; Demuth, 1992; Lewis, 1994), there is very little research focusing on the acquisition in phonology in Southern African languages particularly the very early stages of acquiring Xhosa phonemes. This fact, together with a need for remediation based on guidelines provided by normative data, argue the need for a series of investigations into the phonological acquisition and processing strategies of Xhosa mother-tongue speakers. 
Results from the investigation of Zulu child language conducted by Lanham (1969), show that clicks are amongst the last consonants to be acquired. Prior to their acquisition the following substitutions for clicks are made:

$\begin{array}{ll}{[\mathrm{d}] \text { or }[\mathrm{g}]} & \text { for } / \mathrm{gq} / \\ {[\mathrm{d}]} & \text { for } / \mathrm{gc} / \\ {[\mathrm{s}] \text { or }[\mathrm{ts}]} & \text { for } / \mathrm{ch} / \\ {[\mathrm{t}]} & \text { for } / \mathrm{c} / \\ {[\mathrm{k}]} & \text { for } / \mathrm{x} /\end{array}$

Connelly (1984) conducted a longitudinal study of four Sesotho - speaking children between 1:6 and 4:2. He found that a 10-month-old child imitate all Sesotho clicks, plus several Zulu clicks, but that 3:3 year-olds were still producing /k/ instead of /q/ in spontaneous speech (e.g. Kuthing <Quthing).

Herbert (1990) reports of a study of 22 Zulu-speaking children aged between 1:6 and 9;1 who were observed in speech and two repetition tasks. Errors reveal that preferred click type was palatal /q/.

Mowrer and Burger (1991) studied the articulation of 41 phonemes by Xhosa-speaking children aged between 2:5 and 6 years with respect to the order of acquisition and types of errors. The first two clicks to occur were the voiceless dental click [I] and the palatal [<] /q/ which were acquired at 2:6. The lateral [,,] /x/ was acquired next between 3:6 and 4 years.

Demuth (1992) conducted a one year longitudinal study of four children between 2:1 and 4:6. Children produced clicks in isolation before they produced them in lexical items. Clicks in words began to be used systematically around 3 years, before that, /q/ was produced as /k/.

The work of Lewis (1994) on phonological development is of particular importance $\mathrm{He}$ studied the acquisition of fifteen click consonants used in Xhosa. He studied the phonological tendencies taking place between Xhosa First Language learners when producing Xhosa clicks and the way Xhosa L2 learners and Xhosa L1 aphasics acquire and lose clicks. The ages of the Xhosa First Language speakers were between 1:6 and 5 years. He found that, due to their complexity, clicks are acquired relatively late along the continuum of phonological development although there was an orderly sequence of acquisition relating to place of articulation. Clicks were acquired in four stages commencing at approximately the age of 3 and reaching maturing at 4 as follows:

Stage $1=\quad$ deletion of clicks in words

Stage $2=\quad$ simplication process $(c>\operatorname{tand} q>\operatorname{tand} x>t / k)$

Stage $3=\quad$ click substitution $(c>$ qand $x>c / q a n d q>c / x)$

Stage $4=\quad$ click accompaniments materialise $(\mathrm{ch}>$ ncandgc $>c)$

Stage $5=$ acquisition of clicks

A summary of previous research shows that all studies commenced after 1:5 years. All of the studies, which used experimental data, concluded that click acquisition occurs around the age of 3. To date no longitudinal study had been done from onset of the first words. 
This paper focuses on the acquisition of click consonants by unilingual Xhosa-speaking children between the age of 1 and 3. The results are based on a longitudinal study conducted over one year. The paper will deal with the order of emergence of click consonants as well as the nature of click inventory change over time.

\section{METHOD}

\section{Subjects}

The initial sample consisted of ten boys and ten girls. Ten of the subjects ( 5 males and 5 females were aged 1 and the others (5 males and 5 females) were 2 years old at the start of the project. This age-range was decided upon because it is generally accepted (Ingram, 1976a, 1976b, 1986) that phonological acquisition starts with the first words at 1:6 and ends around 6;0. However it appears that Bantu-speaking children master phonemes at an earlier age than do English speakers (Mowrer \& Burger, 1991; Demuth, 1992). All of the children lived in monolingual Xhosa mother-tongue homes in Gugulethu, a predominantly Xhosaspeaking residential area in the Western Cape, South Africa.

All of the children stayed at home and were cared for by a family member. In all cases their motor, social and language development were within normal limits, as determined by health records and parent interviews. All of them also had normal hearing at the beginning of the study, as assessed by a third year Speech-Language Pathology/Audiology student on a portable audiometer.

To summarise, to be included as participants, children had to meet the following criteria:

- $\quad$ No obvious somatic abnormalities

- $\quad$ No known neurological or cognitive dysfunctions

- $\quad$ No evidence of hearing loss before the commencement of observation

- $\quad$ Xhosa was the only language spoken at home

During the course of data collection 10 children, 7 one-year-olds and 3 two-year-olds, dropped out of the study leaving a total population of ten subjects: 3 one-year-olds ( 2 males and 1 female) and 7 two-year-olds (4 males and 3 females) whose developments were followed for a year. The children dropped out because they had moved from one residential area to another or to far distant areas. Due to the unequal sizes of gender groups no comparison was attempted between phoneme acquisition for female and male subjects. Previous research however on phoneme acquisition, indicates that gender has no significant effect upon such acquisition (Winitz, 1969; Ritterman \& Richter, 1979).

\section{PROCEDURE}

The study was approved by the Cape Town Health Department. Nursing sisters in charge of two health clinics were approached, regarding health records of children. From these records children were selected on the basis of normal birth and health records. Parents of the selected children were approached for permission to include their children in the study. 
Each child's speech was recorded on a fortnightly basis for one year. Each session lasted between 30 minutes and 1 hour. Samples were recorded on audiotapes, using small high quality tape recorders. Notes on the communication situation and target words were taken at the time of the recording to assist with transcription. All recording took place in the children's homes in free play situations. Books and toys were supplied for stimulation.

The data collection was done by eight field workers who were Xhosa first language speakers doing undergraduate or post-graduate studies in Linguistics or Speech Language Pathology. All field workers were trained in data collection and inventory techniques by the two principal investigators. All had previous experience with phonetic transcription. Transcription was done in teams of two using IPA symbols. Samples were listened to repeatedly until a consensus was reached on each sound. The percent reliability between the two transcribers was between 80 and $90 \%$. In cases of disagreement, expert assistance was sought from a trained phonologist.

\section{DATA ANALYSIS}

The data have been consolidated into four age groups, as the changes from one age group to the next were minimal. The final age groups are as follows:

- 1 year to $1: 6$ years

- $1: 7$ to 2 years

- 2 years to $2: 6$ years

- $\quad 2: 7$ years to 3 years

The criteria for determining an emerging sound was when a sound occurred 1-3 times in a sample particularly if it did not occur in all the main positions in the word (such as initial, medical and final). If it occurred in imitation it was considered emerging. A sound that occurred four or more times was considered established or acquired.

\section{RESULTS AND DISCUSSION}

Table 3 below shows that:

- The order of basic acquisition is confirmed: c, $\mathrm{q}>\mathrm{x}$.

- The appearance of all basic clicks is between 1 and 1:6 years for two of the children.

- There is slow development up to 1:6.

- A spurt occurs between 1:7 and 2 years.

- There is a noticeable trend in the development from voiceless to voiced and nasalised clicks.

- The findings are in line with Jakobson's (1968) view that children move from unmarked to more marked phonological structures in the course of acquisition.

As early as between 1 and 1:6 years of age the children began to acquire all three types of clicks although at maximum of $70 \%$ frequency of correct production. This result refutes the assertion by Lewis (1994) that clicks are acquired at approximately the age of 3 and reach 
maturity at 4 . It is also in conflict with the investigation conducated into Zulu child language by Lanham (1969), who found that clicks were the last consonants to be acquired.

\begin{tabular}{|c|c|c|c|c|}
\hline $\begin{array}{c}\text { Frequency of } \\
\text { Correct } \\
\text { Production }(\%)\end{array}$ & 1: 0-1: 6 years & 1:7- 2: 0 years & $\begin{array}{c}\text { 2: } 0 \text { - 2: } 6 \\
\text { years }\end{array}$ & 2: 7-3: 0 years \\
\hline $0-10$ & $\begin{array}{l}{[-] \mathrm{c}} \\
{[,] \mathrm{x}}\end{array}$ & $\begin{array}{l}{[-] \mathrm{c}} \\
{[-\hat{1}] \mathrm{ch}} \\
{[-\&] \mathrm{nc}} \\
{[, 3] \mathrm{gx}} \\
{[<\&] \mathrm{nq}}\end{array}$ & $\begin{array}{l}{[-\hat{\imath}] \mathrm{ch}} \\
{[-3] \mathrm{gc}} \\
{[,] \mathrm{x}} \\
{[, 3] \mathrm{gx}} \\
{[, \&] \mathrm{nx}} \\
{[<] \mathrm{q}} \\
{[<\&] \mathrm{nq}} \\
{[<\hat{\imath}] \mathrm{qh}} \\
{[<3] \mathrm{gq}}\end{array}$ & $\begin{array}{l}{[-\hat{1}] \mathrm{ch}} \\
{[-3] \mathrm{gc}} \\
{[-\& 3] \mathrm{ngc}} \\
{[, 3] \mathrm{gx}} \\
{[,, \& 3] \mathrm{ngx}} \\
{[<\hat{1}] \mathrm{qh}} \\
{[<\& 3] \mathrm{ngq}} \\
{[\mathrm{N}<] \mathrm{nkq}}\end{array}$ \\
\hline $10-20$ & {$[<] \mathrm{q}$} & $\begin{array}{l}{[-\& 3] \mathrm{ngc}} \\
{[,] \mathrm{x}} \\
{[<\hat{\imath}] \mathrm{qh}} \\
{[<3] \mathrm{gq}} \\
{[<\& 3] \mathrm{ngq}}\end{array}$ & $\begin{array}{l}{[-] \mathrm{c}} \\
{[-\&] \mathrm{nc}} \\
{[<] \mathrm{q}}\end{array}$ & \\
\hline $20-30$ & & & & $\begin{array}{l}{[-\&] \mathrm{nc}} \\
{[<] \mathrm{q}} \\
{[<3] \mathrm{gq}}\end{array}$ \\
\hline $30-40$ & & & & $\begin{array}{l}{[,] \mathrm{x}} \\
{[, \&] \mathrm{nx}}\end{array}$ \\
\hline $40-50$ & & & & {$[<] \mathrm{q}$} \\
\hline $50-60$ & & & & {$[-] \mathrm{c}$} \\
\hline $60-100$ & & & & \\
\hline
\end{tabular}

Table 3: The Order of Acquisition of Click consonants

The Table shows that the first three types to emerge were: $[-],[],,[<]$. These results are consistent with findings by Lewis (1994) whose rank order of click acquisition places [-] and [,]first. with [!] as the third click to be acquired. According to Mowrer and Burger (1991), the first two clicks to occur were [-] and [<] which were acquired at two and a half years. The [,,]click occurred next, between 3.6 and 4 years, which was again different from the findings in this study.

Acquisition research on Basotho children (Connelly, 1984; Demuth, 1984, 1986) shows that they develop speech more rapidly than their Western counterparts. Connelly (1984) found that development that takes place between 12 and 17 months in Basotho children occurs 
between 19 and 27 months in Western children. As early as 25 months of age, Basotho children are already using motherese when talking to younger siblings, whereas other studies show that the use of motherese occurs around 4 years of age for American children. Similar evidence for linguistic precocity has been documented by Demuth (1986) for Basotho children Golinkoff (1983) for Kaluli children and Mowrer and Burger (1991) for Xhosa children.

Mowrer and Burger (1991) point out that verbal interaction plays an important role and occurs frequently in the daily lives of Xhosa people. Xhosa speakers also master phonemes at an earlier age than do English speakers. Approximately $80 \%$ of Xhosa phonemes are mastered by Xhosa children before age 3 years, while according to some studies of English speaking children, they only master $40 \%$ of phonemes before the age of 3 years.

In addition to language stimulation, dentition may be an important determinant of early consonant acquisition (Mowrer \& Burger, 1991). Studies of the dentition of Blacks in Southern Africa indicate that they possess large, well-developed jaws and dental arches that are longer and broader than those of most modern populations (Jacobson, 1967). Malocclusions between upper and lower teeth are minimal and teeth are well accommodated. On the other hand, studies of dentition of English speaking White children in Europe and America indicate dental malocclusions are so prevalent as to be considered normal (Mowrer and Burger, 1991:149).

In the present study as well, there was ample evidence of what (Golinkoff, 1983; Demuth, 1986) describe as a rich verbal environment. In their terms, this means that from birth on, the infant is treated as a social being and as an addressee in social interaction. Children are therefore encouraged to verbalize from an early age, and speech is directed to them by the members of their nuclear and extended family. The verbal environment of the Xhosa children in this study was characterised by extensive use of question and prompting routines. The excerpt below, which is a conversation between (Toto) who was 1:9 yrs at the time, the research assistant (RA) and the child's brother (Bro.), provides an example of this.

Toto: Sapha - Give it to me.

Bro.: Uza kuyithini? -What are you going to do with it?

RA: Uza kuya ekrishi namhlanje? - Are you going to the Creche today?

Toto: Ewe. - Yes

RA: Uza kutya ntoni? - What are you going to eat?

Toto: Tyi papa - I'll eat porridge

Toto: Masiye 140 kayoku - Let's go to 140 (Street name)

Bro: Siyokwenza ntoni? - What are we going to do (there)?

Toto: Yocuya - To go and sing

Bro: Uza kucula nabani?

Toto: NoZoyi - Together with Zoyi.

This may have facilitated the acquisition of certain aspects, of the grammar. Table 3 shows the overall order of acquisition of click consonants. It seems that the palatal click is not necessarily acquired first. All three click consonants are produced within the first 18 months though at a lower percentage of correct production percentage of the acquisition of most clicks. The level of correct production reaches $60 \%$ by the age of 3 . 
The corpus shows a developmental tendency in the production of click sounds, starting out slowly (between 1 and 1:6 years) culminating in a spurt (between 1:6 and 3 years) (cf Reich (1986) and Ingram (1989). There is also a noticeable trend in the development from basic voiceless to voiced and nasalized combinations. This process is in line with Jakobson's (1968) view that children move from unmarked to more marked prosodic structures in the course of acquisition. This would seem to be based on the development of the child's vocal tract. This tendency is in keeping with Jakobson's theory of laws of irreversible solidarity. One of these states that children will acquire the basic or unmarked features before the more marked ones (Ingram, 1968)

Further analysis of the present corpus would show to what extent action theory (Fowler, Rubin \& Remez, 1980) relating to consonant vowel association would account for place of articulation of the click consonants. For example, MacNeilage and Davis (1990) investigated three consonant vowel associations in English. They reported that the central vowels [a] and [ə] occurred most often. Next in a labial environment, high front vowels occurred in an alveolar environment and high back vowels, though rare, occurred most often in a velar environment. Preliminary observations on click sounds show that some dental clicks tend to occur with high front vowels while aspirated lateral clicks seem to occur with back vowels. More data are required before firmer conclusions can be reached.

\section{SUMMARY AND CONCLUSION}

Findings on this preliminary study have shown the age and order of click consonants amongst Xhosa-speaking children. Xhosa-speaking children begin using 3 basic clicks from the age of one at the onset of speech. The onset of click production is earlier than previous studies of Xhosa, Zulu and Sesotho have indicated. The acquisition is not complete by three years but is well underway. It takes a while to articulate click consonants, combining clicks and vowels within a word. Previous research focussed on errors rather than emerging abilities. The findings presented in this paper are consistent with other acquisition research regarding the linguistic precocity of children acquiring African languages.

Further analysis of the data is required to identify phonological processes taking place during acquisition. Furthermore the consonant-vowel relationship needs to be investigated. In view of the limited research available on the acquisition of clicks on African languages in general and Xhosa in particular, it is hoped that this research will stimulate debate with respect to acquisition research.

\section{REFERENCES}

CONNELLY, M. 1984. Basotho children's acquisition of noun morphology. Unpublished $\mathrm{PhD}$ dissertation, University of Essex

DEMUTH, K 1984. Aspects of Sesotho language acquisition. Bloomington: Indiana University Linguistics Club 
DEMUTH, K. 1986. Prompting routines in the language socialization of Basotho children. In Schieffelin, B \& E Ochs (Eds), Language socialization across cultures. New York: Cambridge University Press: 82-96.

DEMUTH, K. 1992. Accessing functional categories in Sesotho: Interactions at the morphosyntax interface. In Meisel, J (Ed.). The acquisition of verb placement: Functional categories and V2 phenomena in language development. Dordrecht: Kluwer Academic Publishers: 83-107.

DOKE CM. 1926. The phonetics of the Zulu language. Johannesburg: University of the Witwatersrand Press.

DOWNING, LJ. 2001. Xhosa. In Gary, J \& C Rubino (Eds), Facts about the world's languages. New York: The HW Wilson Company.

FOWLER, CA, P RUBIN, RE REMEZ \& MT TURVEY. 1980. Implications for speech production of a general theory \& actions. In Butterworth, B (Ed.), Language production Vol 1: Speech and talk. London: Academic Press.373-420.

GOLINKOFF, RM (Ed). 1983 The transition from prelinguistic to linguistic communication. Hillsdale, New Jersey: Lawrence Erlbaum Associates, Publisher.

GREENBERG, JH. 1970. The languages of Africa. Bloomington: Indiana University Press.

HARINCK, G. 1972. Interaction between Xhosa and Khoe: Emphasis on the period 16201750. In I Thompson (Ed), African Societies in Southern Africa. London: Heinemann.

HERBERT, RK. 1983. Clicks in normal and delayed acquisition of Zulu. Paper presented at the Tenth International Congress of Phonetic Sciences, Utrecht.

HERBERT, RK. 1990. The relative markedness of click sounds: Evidence from language change, acquisition and avoidance. Anthropologica Linguistics, 32 (1-2): 120-138.

HERBERT, RK. 1996. The Sociohistory of clicks in Southern Bantu. Anthropological Linguistics, 32(3-4): 120-38.

INGRAM, D. 1976a. Current issues in child phonology, In Donald M. Morehead (Ed.), Normal and deficient child language. Baltimore: University Park Press. 3-27.

INGRAM, D. 1976b. Phonological disability in children. London: Edward Arnold

INGRAM, D. 1986. Phonological development: Production. In P Fletcher \& M Garman (Eds), Language acquisition. London: Cambridge University Press: 55-68.

INGRAM, D. 1989. First language acquisition. New York: Cambridge University Press.

JACOBSON, A. 1967. The Bantu dentition: A morphological and metric study of Bantuspeaking negroids. $\mathrm{PhD}$ dissertation, University of Witwatersrand 
LADEFOGED, P \& TRAILL, A. 1994. Clicks and their accompaniments. Journal of Phonetics, 22: 33-64.

LANHAM, LW. 1964. The proliferation and extension of Bantu phonemic systems influenced by Bushman and Hottentot. In HG Lunt (Ed.), Proceedings of the Ninth International Congress of Linguistics. The Hague: Monton.

LANHAM, LW. 1969. Gerative phonology and the analysis of Nguni languages. Lingua, 24: 155-162.

LEWIS, PW. 1994a Aspects of the phonological acquisition of clicks in Xhosa. Unpublished MA thesis, University of Stellenbosch.

LEWIS, PW. 1994b. The acquisition of clicks by non-mother-tongue speakers. Paper presented at the Conference for the Language Professions. University of Stellenbosch: Stellenbosch, April 1994.

LEWIS, PW \& JC ROUX, JC. 1996. A phonological process analysis of the acquisition and loss of clicks in Xhosa South. African Journal of African Languages, 16 (1): 1-7.

LOUW, JA. 1974. The adaptation of udu-click consonants in Xhosa'. In Khoisan Linguistic Studies, 3: 74-92.

LOUW, JA. 1979. A preliminary survey of Khoi and San influence in Zulu. In Khoisan Linguistic Studies, 8:8-21.

MACNEILAGE, PF \& DAVIS, B. 1990. Acquisition of speech production. In YeniKomshian, G, J Kavanagh \& CA Ferguson Child Phonology, Vol.1: Production. New York: Academic Press: 55-68.

MADDIESON, I \& P LADEFOGED. 1993. Phonetics of partially nasal consonants. In Huffman, MK \& RA Krakow (Eds), Nasals, nasalization and the velum. San Diego: Academic Press.

MAGI, LM. 1990. The diffusion of click sounds from Khoisan to Bantu languages in Southern Africa. SA Geographer, 17 (1/2):114-123. See text where you refer to 1990.

MESTHRIE, R (Ed.). 2002. Language and social history. Cape Town: David Phillip.

MOWRER, DE \& BURGER, S. 1991. A comparative analysis of phonological acquisition of consonants in the speech of 25-6-year old Xhosa and English speaking children. Clinical Linguistics \& Phonetics, 5 (2): 139-164.

REICH, PA. 1986 Language development. Englewood Cliffs, New Jersey: Prentice Hall.

RITTERMAN, SI \& UEM RICHTER, UEM. 1979. An examination of the articulatory acquisition of Swedish phonemes. In Hollien, $\mathrm{H}$ \& $\mathrm{P}$ Hollien (Eds), Current issues in Linguistics Theory (Vol 9) Part III (Amsterdam: John Benjamin). 17-19. 
SUZMAN, S. 1982. Strategies for acquiring Zulu concord. South African Journal of African Languages, 2: 53-67.

WADE, N. 2003. In click languages, an echo of the tongues of the ancients. New York Times, Section F, Column 2, Science desk, p 2, 18 March 182003.

WINITZ, H. (1969). Articulation, acquisition and behavior. New York: Appleton-CenturyCrafts

\section{Biographic Note}

Sandile Gxilishe is at present an Associate Professor in the School of Languages and Literatures at the University of Cape Town, Private Bag, Rondebosch, 7701, South Africa. His chief interests are Acquisition Research in both First and Second Language. He is currently conducting research on the Acquisition of Xhosa by monolingual children in order to establish normative data for Xhosa. Email: sandile@ humanities.uct.ac.za 